Website: http://jsci.utq.edu.iq Email: utjsci@utq.edu.iq دراسة فسلجية ووبائية عن مرض الحمى السوداء (Kala-azar) في محافظة ميسان \author{
نضال عبداله هاشم \\ قسم التمريض - الدعهذ التقني- الطبي - العمارة
} زينب عبد الجبار رضا العلي قسم علوم الحياة - كلية العلوم - جامعة ميسان

$$
\begin{aligned}
& \text { حيدر زعاطي عبادي } \\
& \text { شعبة المختبرات ـ مستثفى الصدر العام - ميسان }
\end{aligned}
$$

الخلاصة: الاطفال , اذ تم قياس قيمـة انزيمات المصل Glutamic Pyruvic و Oxaloacetic Transaminase(GOT) Alkaline Phosphatase (ALP) والبروتين الكلي والبيلروبين الكلي في دم 50 طفلا مصابا بالحمى

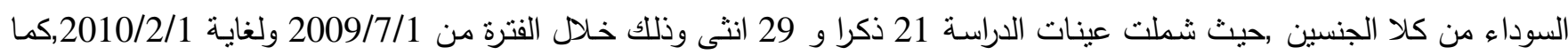

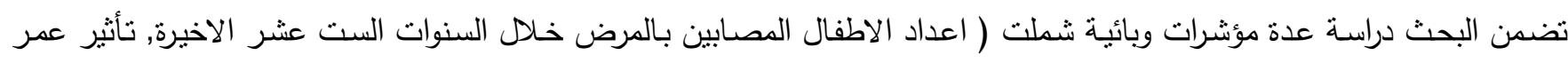

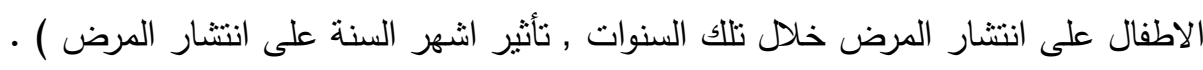

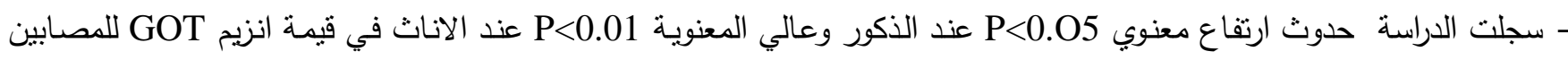

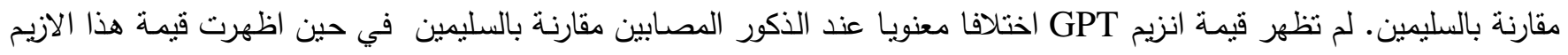

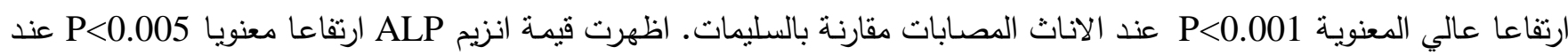

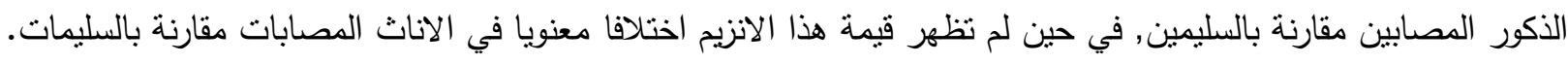

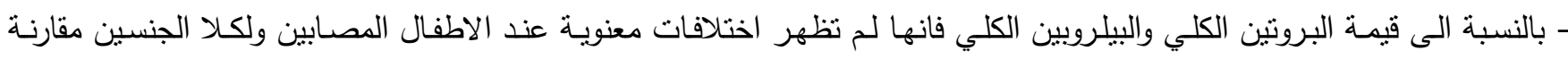

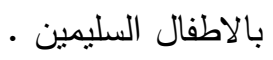
- اختلفت نسب الاصـابة بهذا المرض بين الاطفال خـال السنوات الست عشر الاخيرة ,اذ سجلت سنة 2007 اعلى نسبة لاصابة

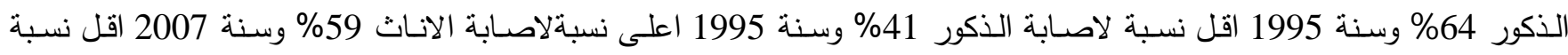

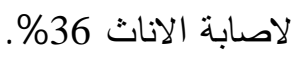
- سجلت الفئة العمرية 1 -2 سنة اعلى عدد لاصابات الاطفال بهذا المرض اذ بلغ مجموع اصابتها 961 اصابة بينما سجلت الفئة

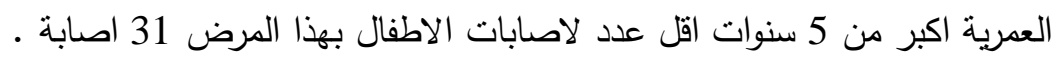
- ان لاشهر السنة تأثثر على عدد الاطفال المصابين بالمرض , اذ كانت اعلى نسبة للاصـابة خـلال شهر كانون الثاني اذ بلغت 17.7\% واقلها خلال شهر اب اذ بلغت 2.4\%. 
ثنانوية اخرى (8) ـ وقد ذكر (9) ان سبب وفاة المرضى يعود الى التهاب شغاف القلب وفقر الدم وزحار وتسمم الدم وهزال واخيرا توقف القلب .

نظرا لانتثار المرض في محافظة ميسان لكثرة الدناطق الريفية

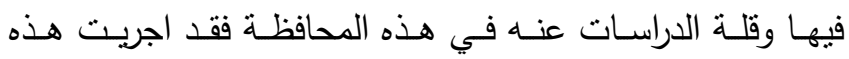
الدراسة والتي تهذف الى معرفة مدى انتشار المرض بين الاطفال

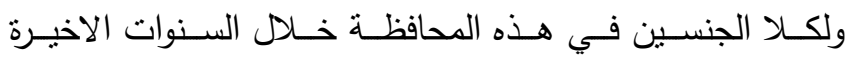

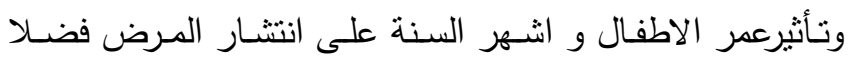
عن دراسة بعض المعايير الكيموحيوية لدى الاطفال المصابين به

المو اد وطر ائق العمل: أخذت عينات هذه الدراسة من الاطفال يعانون من اعراض مرض اللثمانيا الحشوية والذين يترددون على مستشفى الصدر العام لغرض الفحص الطبي واجراء اختبار اللثمانيا الحشوية

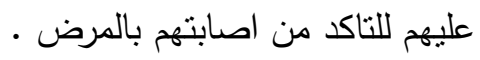
أجرى اختبار Kala azar detect rapid test على الاطفال المراجعين للمستشفى , وعلى اسـاس هذا الاختبار تم

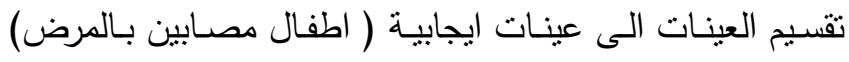
وعينات سلبية ( اطفال سليمين ) والتي اعتبرت مجموعة سيطرة

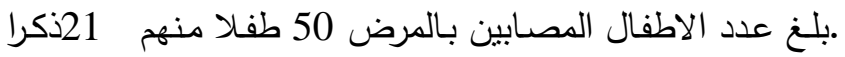
و29 انثى والذين تراوحت اعمارهم مـا بين 2 شـهر - 7 سنة الفنة

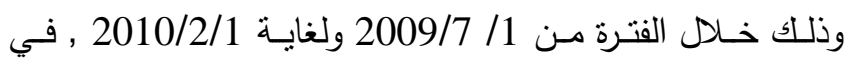

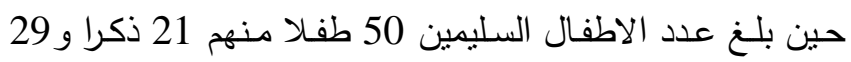
انثى وذلك خلال الفترة نفسها المذكورة اعلاه .

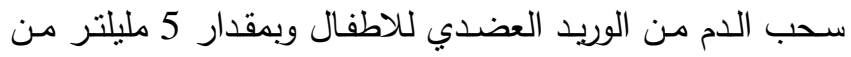

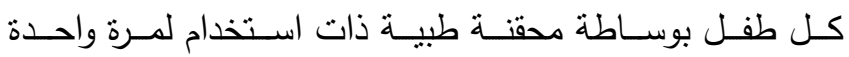
المادة Disposable syringe

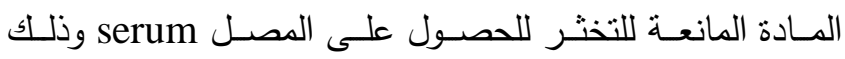

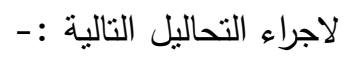

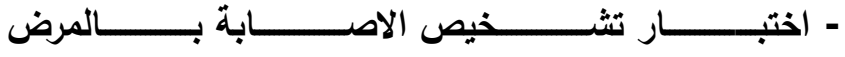
Immunochromatographic strip assey
المقدمة: بعد مرض اللثشمانيا الحشوية (الكلاازار Kala-azar) من الامراض الششتركة الواسعة الانتثار , والذي يسببه طفيلي وحيد الإني

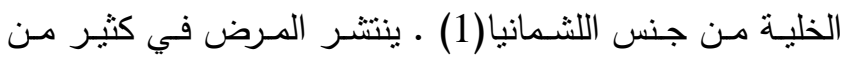
بلدان العالم وتتفاوت صفاته المرضية والوبائية باختلاف المنطقة

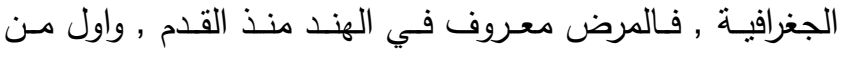

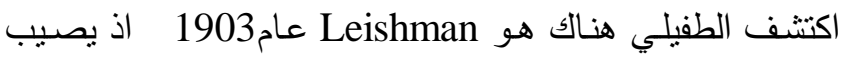
البالغين وله مميزات سريرية خاصـة اهمها الطفح الجلدي بعد الطداك Post Kala-azar Dermal الثفاء وتدعى هذه الظاهرة Leishmaniasis (PKDL)

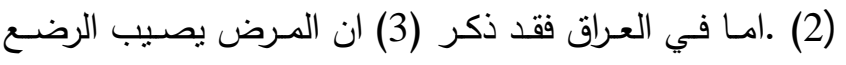

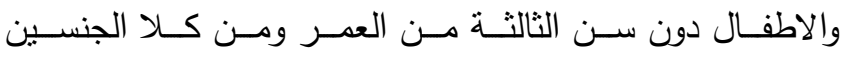

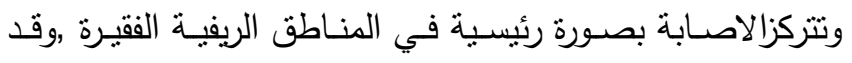
يصيب كبار السن اذ سجل (4) بعض الاصـابات في انشخاص

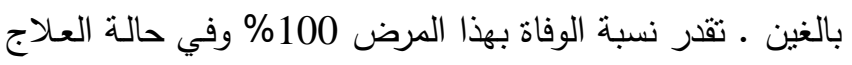

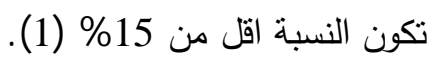

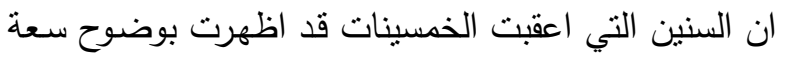

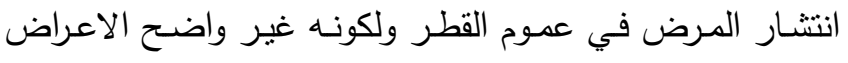
والمصاب به قد يحتفظ بقسط كبير من النشاط والحيوية بالرغم

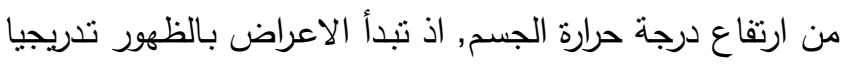

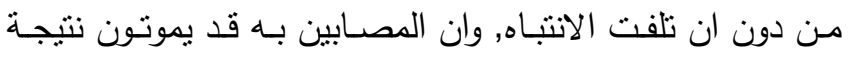

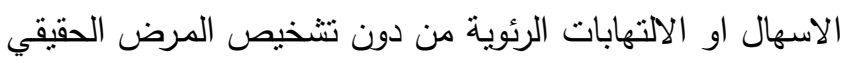

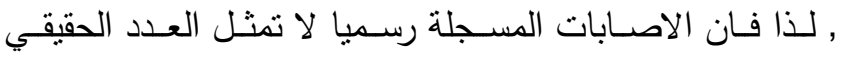

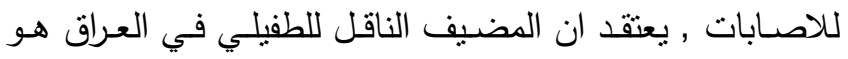

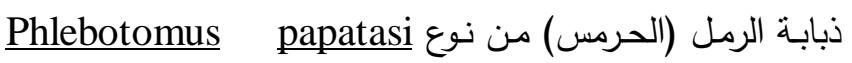

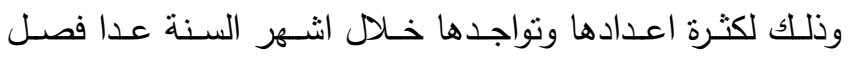
الثناء وان المضيف الخازن للمرض هو القوارض والكلاب(5) وفي العراق استطاع (6) عزل الطفيلي من الكلاب ـ تتراوح مدة

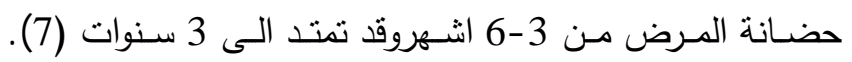

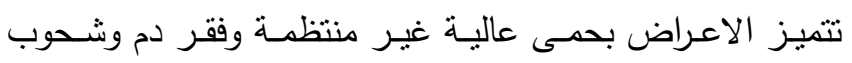
وضـف في الثـهية وفقدان في الـوزن وانتفاخ البطن ويثـير

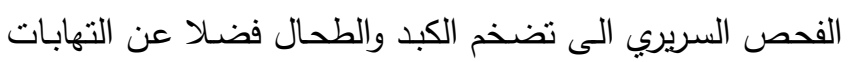


الاطفال السليمين (50) طفلا ايضا منهم 21ذكرا ونسبتهم 42\%

$$
\text { و29 انثى ونسبتهن 58\% . }
$$

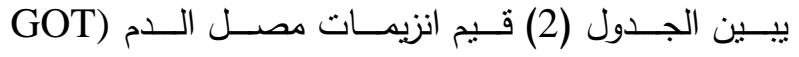

و ALP و ALT لكل مـن الذكور والانـاث المصـابين والسـليمين ويلاحـظ منــهـ ان قيمـة انـزيم GOT ارتفعـت ارتفاعـا معنويــا

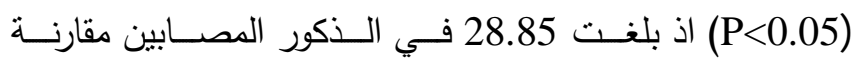
بالسليمين اذ بلغت 16.90 والثشئ نفسـه ينطبق على قيمته عند

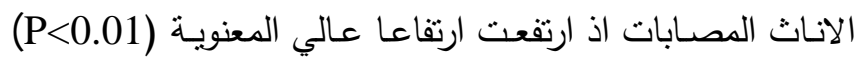
عنـــ الانـاث المصـابات اذ بلغـت قيمتـه 68.62 مقارنــة بالانـاث السليمات اذ بلغت قيمته 10.14 (الجدول 2). اما بالنسبة الى قيمة انزيم GPT فيلاحظ من الجدول نفسه

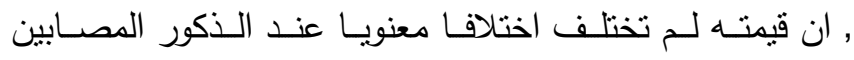
11.80 مقارنـة بالذكور السليمين 9.47, في حين لوحظ ارتفاعا عـالي المعنويـة (P<0.01) في قيمـة هـذا الانـزيم عند الانـاث

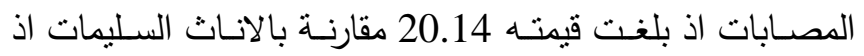

$$
\text { بلغت قيمته } 9.48 \text { (الجدول 2). }
$$

وفيما يخص قيمة انزيم ALP فيلاحظ من الجدول (2) ان قيمة هذا الانزيم اظهرت ارتفاعا معنويا (P<0.05) عند الذكور المصـابين اذ بلغت 131.71 مقارنــة بالذكور السـليمين اذ بلغتـ 106.19 , وعلى الرغم من الارتقاع الحاصل في قيمة هذا الانزيم

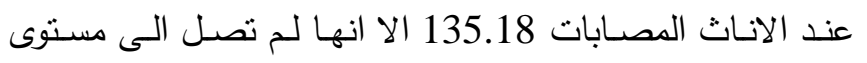
المعنوية مقارنة مع الاناث السليمات 111.66 (الجدول 2). يظهر الجدول (3) قيم البروتين الكلي والبيلروبين الكلي عند

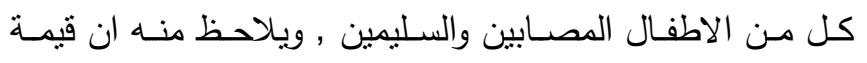
البروتين الكلي لـم تختلف اختلافـا معنويـا في كل مـن الذكور

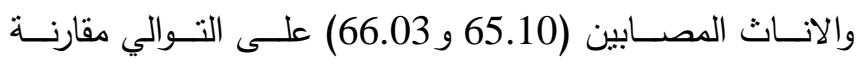

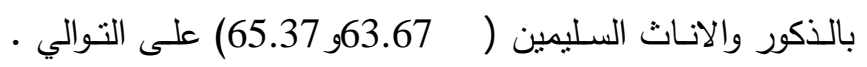

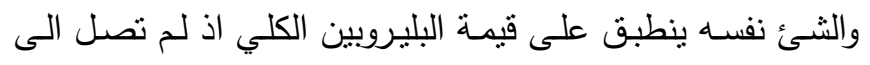
مستوى المعنويـة في كل من الذكور والاناث المصـابين اذ بلغت قيمتـه (13.33و 10.64) على التوالي مقارنـة بالـكور والانـاث السليمين اذ بلغت قيمته (10.64 و 13.07 (12.07) على التوالي.
أجرى هذا الاختبار استتادا على الطريقة المذكورة من قبل (10). - التحاليل الكيموحيوية لمصل الدم وشملت كل من : - قياس فعالية انزيمي GOT,GPT استخدمت طريقة Enzymetic Colorimeteric المذكورة من قبل (11) لقياس فعالية الانزيمين. - قياس فعالية انزيم ALP استخدمت طريقةEnzymetic Colorimeteric المذكورة من قبل (12) لقياس فعالية الانزيم • - تقدير البروتين الكلي اسـتخدمت الطريقـة المـذكورة مـن قبـل (13 ) لغـرض تقــير

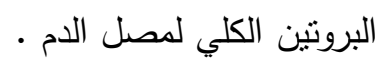

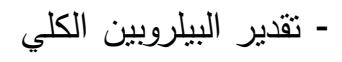

استخدمت طريقة الديازو Diazo method المذكورة من قبل (14) لغرض تقدير البيلروبين الكلي لمصل الدم •

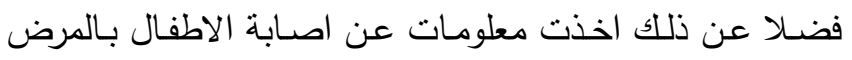

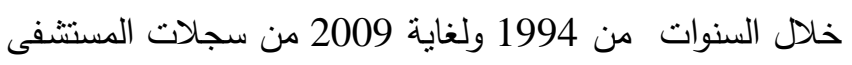

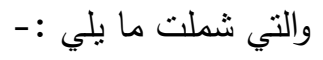
1 - عدد الاطفال المصابين بالمرض من الذكور والاناث خـال تلك السنوات 2 - تأثثر عمر الاطفال على عدد الاصابات بالمرض. 3 - ناثير اشهرالسنة على عدد الاصابات بالمرض • التحليل الاحصائي :

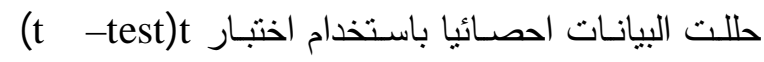

واختبار مربع كاي (X-squre) وذلك اعتمادا على (15). النتائج: يتضـــح مـن الجــدول (1)ان اعــداد الاطفــال الـــكور المصـابين بمـرض الكـلازار بلـنغ 21 ذكـرا ونسبتهم 42\% وعدد الانـاث المصـابات بهذا المـرض بلـنع 29 انثى ونسـبتهن 58\%

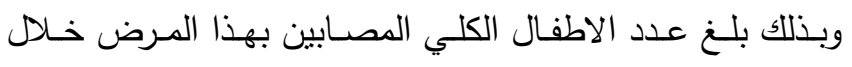
الفترة من 2009/7/1الى 2010/2/1 (50) طفلا , وبلـغ عدد 
(40.5\%) مقارنة بالفئات العمرية الاخرى والتي اظهرت انخفاضـا معنويـا في عدد الاصـابات بتقدم عمر الاطفـال اذ سـجلت الفئة العمريـة اكبر من 5 سنوات اقل عدد للاصـابات اذ بلـن مجموع

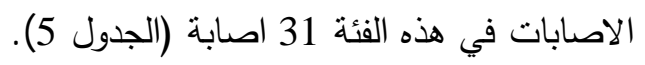
يبين الجدول(6) اعداد الاطفال المصابين بمرض الكلاازار حسب اشـهر السـنة خـلال السـوات مـن 1994 ولغايـة 2009

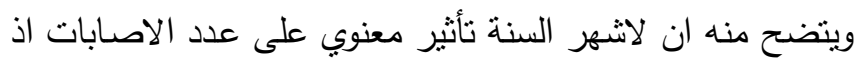
كانت اعلى نسبة اصـابة خـلال شـهر كانون الثاني بعدد 420 اصـابة وبنسبة (17.7\%) يليها شـهر شباط بعدد 400 اصـابة وبنسبة (16.8\%) واقل نسبة اصـابة كانت خـل شهر أب بعدد

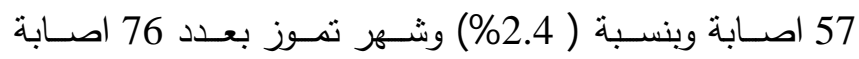
وبنسبة (3.2\%) وان اعلى نسبة اصابة خلال السنوات 1994 2009 تقع ضمن سنة 2003 بعدد 271 اصابة وبنسبة (11\%) تليها سنة 1994 بعدد 223 اصابة وبنسبة (9.4\%) واقل نسبة اصابة كانت في سنة 2008 بعدد 59 اصابة وبنسبة (2.4\%) .

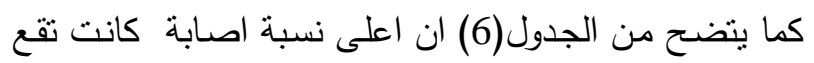

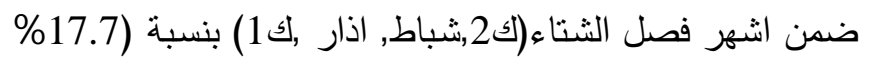

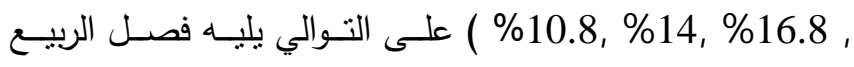

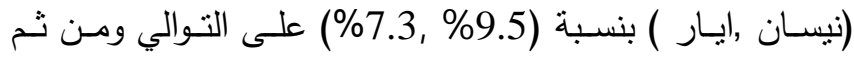

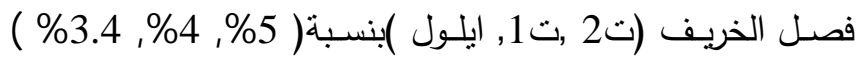
على التوالي واقل نسبة اصـابة كانت خلال فصل الصيف (تموز ,
يبــين الجـدول(4) اعـداد الاطفــال مـن الــكور والاتــاث المصـابين بمرض الكـلازار خـلال (16) سنة الاخيرة من 1994 ولغاية 2009 ونسبهم المئوية ويلاحظ من خلاله ان اعلى نسبة اصـابة بمـرض الكـلازار للـكور كانـت في سـنة 2007بنسـبة (64\%) تليها سنة 2009 وبنسبة(51\%) واقلها كانت في سنة

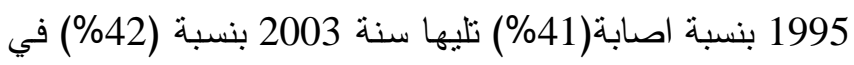
حين كانت اعلى نسبة اصـابة في الانـاث خـلا سـنة 1995

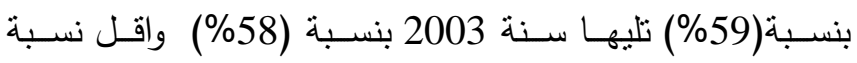
للاصـابة خـلال سـنة (2007) بنسـبة (36\%)تليهـا سـنة 2005

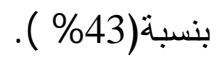

ويظهر مـن الجدول (5) اعداد الاطفال المصـابين بمرض لهر

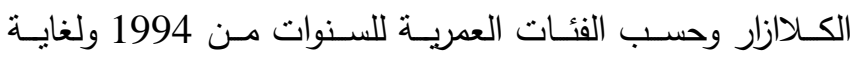
2009 حيث كانت اعلى اصابة للفئة العمرية (شهر - سنة واحدة) خلال سنة 2003 بعدد 104 اصـابة ونسبة(38\%) واقلها خـلا سله سنة 2007 بعدد 25اصابة وبنسبة (42\%)في حين كانت اعلى اصـابة في الفئة العمريـة(1 -2 سـنة) خـلال سـنة 2003 بعدد 123 اصـابة وبنسبة ( 45\% ) واقل اصـابة خـلال سـنة 2007

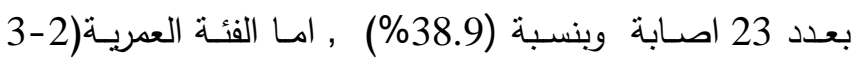
سنة) فقد كانت اعلى اصـابة فيها خـلال سنة 2004 بعدد 42 اصـابة بنسبة(23.5\%) واقل اصـابة خـلال سنة 1996 بعدد 11اصـابة ونسبة ( 12.9\% ) اما الفئة العمرية (3 -4سنة) فقد كانــت اعلىى اصـابة لهـا فـي سـنة 2004 بعـدد 27 اصـابة وبنسـبة(12.5\%) واقـل اصـابة فيهـا كانـت خـلال ســنة 2007

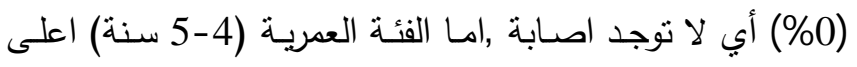
اصـابة فيها كانـت خـلد سـنة 1994 بعدد 18 اصـابة ونسبة (8\%) واقل اصابة في سنة 2008 (0\%) أي لا توجد اصابة في حين كانت الفئة العمرية (اكبرمن 5 سنة)اعلى اصسابة فيه كانت خلال سنة 2005 بعدد 5 اصابة ونسبة (6\%) ولا توجد اصابات في هذه الفئة العمرية خلال السنوات(1994 - 2003). ويلاحظ من الجدول نفسه ان عمر الاطفال له تأثنير معنوي

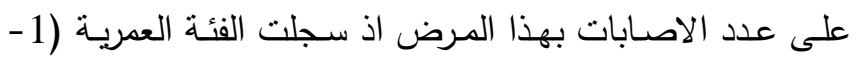
2ســنة)اعلى عـدد للاصــابات اذ بلغـت 961 اصـابة وبنسـبة 
الجدول (1) :عدد الأطفال المصابين بمرض الكلازار

و السليمين ونسبتهم المئوية حسب الجنس خلال مدة الدراسة الجنة

\begin{tabular}{|c|c|c|c|c|}
\hline \multicolumn{2}{|c|}{ 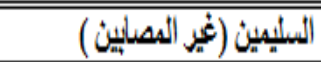 } & \multicolumn{2}{|c|}{ الثصبينين } & \multirow{2}{*}{ الجنس } \\
\hline التنبية المئوية \% & 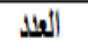 & التنبية المنوية \% & |العلا & \\
\hline 42 & 21 & 42 & 21 & الأكلزد \\
\hline 48 & 29 & 58 & 29 & الإداث \\
\hline 100 & 50 & 100 & 50 & 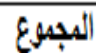 \\
\hline
\end{tabular}

الجدول (2) : قيم أنزيمات مصل الدم للذكور والإناث المصابين و السليمين (الذكور n=21 و الاناث n=29) خلال مدة الدر اسبة

\begin{tabular}{|c|c|c|c|c|c|c|}
\hline \multicolumn{3}{|c|}{ الإناث } & \multicolumn{3}{|c|}{ الثكوف } & \multirow{2}{*}{ الألنزيمات } \\
\hline ALP IU/L & $\begin{array}{l}\text { GPT } \\
\text { IU/L }\end{array}$ & $\begin{array}{l}\text { GOT } \\
\text { IU/L }\end{array}$ & ALP IU/L & $\begin{array}{l}\text { GPT } \\
\text { IU/L }\end{array}$ & $\begin{array}{l}\text { GOT } \\
\text { IU/L }\end{array}$ & \\
\hline $135.18 \pm 7.45$ & $20.14 \pm 4.13$ & $68.62 \pm 11.71$ & $131.71 \pm 13.21$ & $11.8 \pm 1.33$ & $28.85 \pm 5.51$ & المصنبين \\
\hline $111.66 \pm 69.46$ & $9.48 \pm 1.13$ & $10.41 \pm 0.98$ & $106.19 \pm 10$ & $9.47 \pm 0.92$ & $16.90 \pm 1.76$ & السليمين \\
\hline 1.363 (NS) & $2.60(\mathrm{~S})$ & $5.017(\mathrm{~S})$ & $1.967(\mathrm{~S})$ & $0.69(\mathrm{NS})$ & $2.17(\mathrm{~S})$ & قالمحسوبة \\
\hline
\end{tabular}

الأرقام تمثل المعدلات + الخطأ القياسي

قيم t الجدولية تحت مستوى احتمالي 0.05 و 0.01 ودرجات حرية 28.20 هي 1.725 و 1.701و 2.528و 2.467 على التوالي . الجدول (3) : قيم البروتين الكلي والبيلروبين الكلي للاككور والإناث المصابين و السليمين

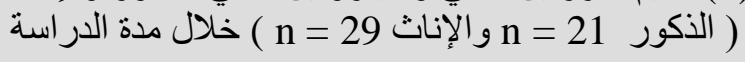

\begin{tabular}{|c|c|c|c|c|}
\hline \multicolumn{2}{|c|}{ الإخاث } & \multicolumn{2}{|c|}{ الأكور } & \multirow{2}{*}{ الجنس } \\
\hline البيلزوينين الكلي & البروثنين الكلي & الثيلزوبين الكلي & البروثين الكلي & \\
\hline $13.63 \pm 0.97$ & $66.03 \pm 1.26$ & $13.33 \pm 1.56$ & $65.10 \pm 2.56$ & المصابيني \\
\hline $12.07 \pm 0.58$ & $65.37 \pm 2.90$ & $10.64 \pm 0.38$ & $63.67 \pm 3.37$ & السليمِيث \\
\hline $1.62(\mathrm{NS})$ & $0.530(\mathrm{NS})$ & $1.566(\mathrm{NS})$ & $0.557(\mathrm{NS})$ & قيَم t المحسوية \\
\hline
\end{tabular}

الأرقام تمثل المعدلات \pm الخطأ القياسي قيم t الجدولية تحت مستوى احتمالي 0.05 ودرجات حرية 28.20 هي 1.725 و 1.70 لعلى التوالي. 
الجدول (4) : عدد الأطفال من الذكور والإناث المصابين بمرض الكلاأزار خلال السنوات من 2009-1994

\begin{tabular}{|c|c|c|c|c|}
\hline التسبة المنوية \% & عـدد الإناك & التسبة المنوية \% & عـدد الثآكوف & الستة \\
\hline 51 & 113 & 49 & 110 & 1994 \\
\hline 59 & 92 & 41 & 63 & 1995 \\
\hline 55 & 47 & 45 & 38 & 1996 \\
\hline 53 & 83 & 47 & 43 & 1997 \\
\hline 54 & 74 & 46 & 62 & 1998 \\
\hline 57 & 69 & 43 & 53 & 1999 \\
\hline 57 & 104 & 43 & 78 & 2000 \\
\hline 55 & 42 & 45 & 34 & 2001 \\
\hline 53 & 97 & 47 & 85 & 2002 \\
\hline 58 & 157 & 42 & 114 & 2003 \\
\hline 56 & 122 & 44 & 94 & 2004 \\
\hline 43 & 77 & 57 & 101 & 2005 \\
\hline 53 & 62 & 47 & 56 & 2006 \\
\hline 36 & 21 & 64 & 38 & 2007 \\
\hline 51 & 51 & 49 & 49 & 2008 \\
\hline 49 & 53 & 51 & 56 & 2009 \\
\hline 53 & 1264 & 47 & 1104 & المجمـوع \\
\hline
\end{tabular}

الجدول (5) : عـــد الأطفال مــن الذكور و الإناث المصابين بمرض الكلازاز و وحسب الفئات العمرية للسنوات من 1994 ولغاية 2009 ـ والانت

\begin{tabular}{|c|c|c|c|c|c|c|}
\hline اكبز من 5سنولت & |5-4 سنة & 4-3 سنة & 3-2 سنة & 1-2 سنة & شهز - سنة واحدة & السئة \\
\hline- & 18 & 17 & 20 & 82 & 86 & 1994 \\
\hline- & 7 & 13 & 17 & 55 & 63 & 1995 \\
\hline- & 1 & 03 & 11 & 22 & 48 & 1996 \\
\hline- & 4 & 07 & 16 & 60 & 69 & 1997 \\
\hline- & 3 & 11 & 18 & 56 & 48 & 1998 \\
\hline- & 3 & 9 & 15 & 44 & 51 & 1999 \\
\hline- & 3 & 6 & 21 & 87 & 65 & 2000 \\
\hline- & 1 & 4 & 13 & 31 & 27 & 2001 \\
\hline- & 4 & 16 & 24 & 79 & 59 & 2002 \\
\hline- & 4 & 10 & 30 & 123 & 104 & 2003 \\
\hline 8 & 7 & 27 & 42 & 78 & 54 & 2004 \\
\hline 11 & 6 & 6 & 20 & 72 & 63 & 2005 \\
\hline 4 & 2 & 6 & 18 & 45 & 43 & 2006 \\
\hline 3 & 2 & - & 6 & 23 & 25 & 2007 \\
\hline 2 & - & 5 & 16 & 50 & 27 & 2008 \\
\hline 3 & 3 & 6 & 13 & 54 & 30 & 2009 \\
\hline 31 & 68 & 146 & 300 & 961 & 862 & المجموع \\
\hline
\end{tabular}


جدول (6): عـــدد الأطفــــال المصابين بمرض الكـلاز ار وحسب أثشر السنـة خــــــلال للسنوات

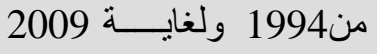

\begin{tabular}{|c|c|c|c|c|c|c|c|c|c|c|c|c|c|}
\hline المجموع & $1^{9}$ & $2=$ & $1=$ & أيلول & نب & تموذ & حزيرلن & أيلز & تيسن & آذار & تنبلط & $2^{9}$ & شهر \\
\hline 223 & 24 & 15 & 2 & - & 3 & 5 & 8 & 19 & 31 & 30 & 38 & 48 & 1994 \\
\hline 155 & 4 & 5 & 5 & 6 & 2 & 8 & 5 & 16 & 28 & 34 & 17 & 25 & 1995 \\
\hline 85 & 18 & 12 & 6 & 1 & 1 & 2 & 2 & 1 & 11 & 12 & 13 & 6 & 1996 \\
\hline 156 & 12 & 23 & 4 & 6 & 3 & 11 & - & 7 & 17 & 21 & 16 & 36 & 1997 \\
\hline 136 & 17 & 7 & 7 & 5 & 3 & - & 5 & 10 & 6 & 19 & 25 & 32 & 1998 \\
\hline 122 & 16 & 6 & 7 & 6 & 3 & 7 & 5 & 6 & 7 & 15 & 24 & 20 & 1999 \\
\hline 182 & 24 & 6 & 10 & 4 & 3 & 8 & 10 & 6 & 13 & 26 & 44 & 28 & 2000 \\
\hline 76 & 2 & - & 6 & - & 3 & 2 & 5 & 14 & 6 & 10 & 9 & 19 & 2001 \\
\hline 182 & 22 & 9 & 7 & 10 & 6 & 7 & 15 & 9 & 14 & 29 & 27 & 27 & 2002 \\
\hline 271 & 37 & 13 & 20 & 16 & - & 6 & 22 & 32 & 29 & 24 & 21 & 51 & 2003 \\
\hline 216 & 32 & 9 & 9 & 12 & 7 & 9 & 13 & 23 & 18 & 24 & 42 & - & 2004 \\
\hline 178 & 18 & 8 & 6 & 5 & 5 & 2 & 7 & 8 & 10 & 19 & 37 & 53 & 2005 \\
\hline 118 & 5 & - & 3 & - & 4 & 2 & 12 & 15 & 17 & 20 & 21 & 19 & 2006 \\
\hline 59 & 3 & 3 & 2 & 2 & 2 & 3 & - & - & 4 & 5 & 18 & 17 & 2007 \\
\hline 100 & 6 & 2 & - & 6 & 4 & 1 & 6 & 4 & 4 & 20 & 25 & 22 & 2008 \\
\hline 109 & 17 & 5 & 1 & 3 & 8 & 3 & 6 & 4 & 10 & 12 & 23 & 17 & 2009 \\
\hline 2368 & 257 & 123 & 95 & 82 & 57 & 76 & 121 & 174 & 225 & 338 & 400 & 420 & المجموع \\
\hline
\end{tabular}

الدراسـة الحاليـة اعـداد ونسـب حـالات الاصـابة بمـرض الحمى السوداء (الكلاأزار )حسب الجنس اظهر زيادة نسبة الاصـابة في

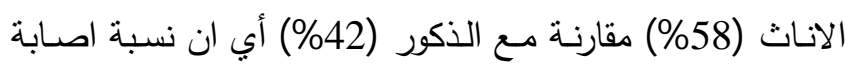

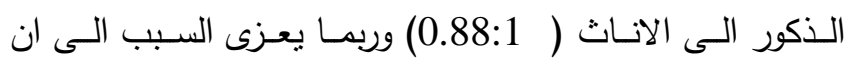
النماذج التي اخذت من الاناث اكثر من الذكور مما يزيد عدد الاهد الحالات الموجبة, وهي تختلف مع ماذكر من قبل (6)حيث بلغت

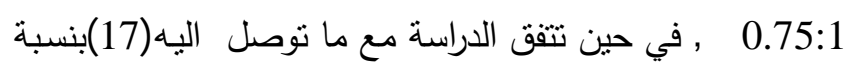

المناقشة: تعد امراض اللثمانيا من الامراض المشتركة التي لها اهمية

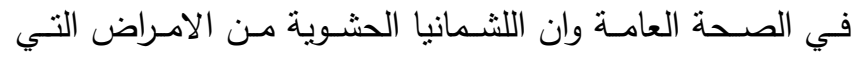
لاتزال تثثر القلق بسبب تزايدها في السنوات الاخيرة في مختلف

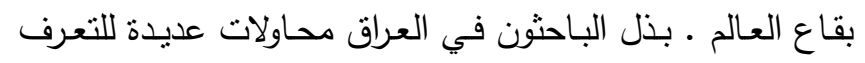

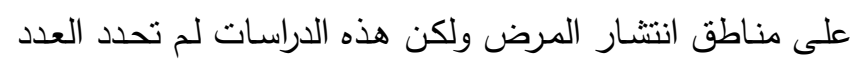
الحقيقي للاصابات في كل محافظة من محافظات القطر بينت 
اختلافا معنويا في كل من الذكور والاناث المصـابة مقارنة مـع

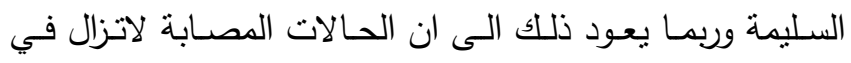
مراحلها الاولية ولم تحدث ضرر كبير في الانسجة المسؤولة عن

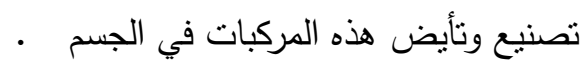
اما البيلروبين يتكون في الاصدل من تلف كريات الدم الحمر ويتخلص الجسم من الكريات المعهرة عن طريق خلايـا الجهاز الثـبكي البطـاني وخاصــة الموجـودة في الكبـد والطحسال ونخـاع العظم $(11,25)$ وان حدوث اية اضطرابات او عرقلة في عملية ايض البيلروبين يؤدي الى مرض اليرقان ومنها اليرقان الكبدي الذي يعزى الـى فنـل الكبـد في قدرتـه على اقتـران البيلـروبين

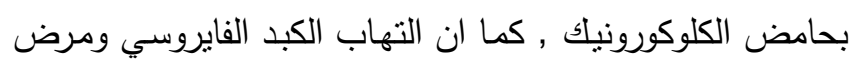

تليف الكبد يؤدي بدوره الى زيادة البيلروبين (25).

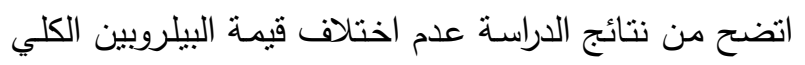
في كل من الذكور والانـاث المصـابة مقارنـة مـع السليمة عدم

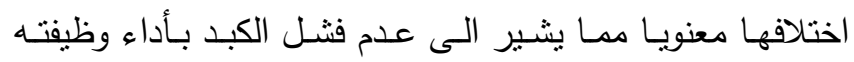

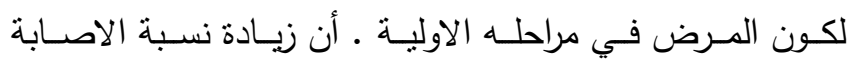

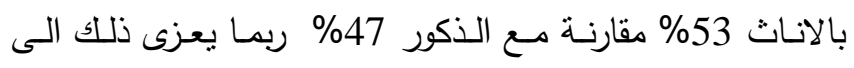

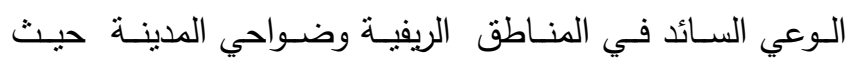
مناطق انتشار المرض مما يؤكد الاهتمام بعلاج الذكور اكثر من

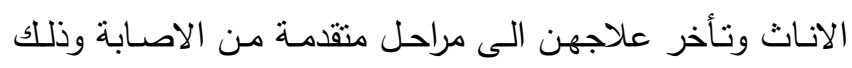

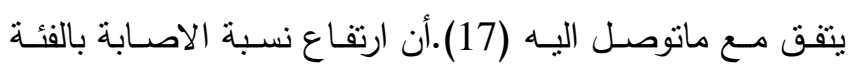

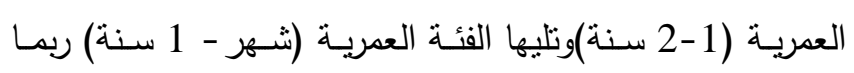
يعزى السبب في ذلك الى ضـعف الاستجابة المناغيـة الخلويـة cell mediated immunity(C.M.I.) ماتوصل اليـه (3,26) الذين ذكروا ان المرض يصـيب الرضـع والاطفال دون سن الثالثة من العمر من كـلا الجنسين , وذكر (17) ان الاصـابات تتركز في السـنة الاولى مـن العمر واشـار (27) الى ان اعلى نسبة اصـابات سجلت بعمر سنة - اقل من الاصن

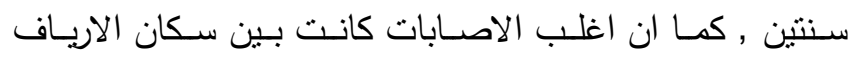
وضـواحي المدينـة وتكثر بـين الاطفال مـن كـلا الجنسين (18)

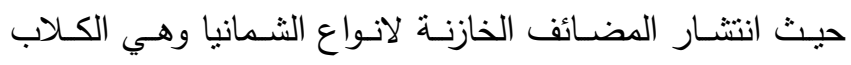

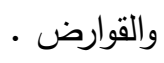

(1.5:1) في حين ذكر كل من (18,19)ان المرض يكثر بين الاطفال من كلا الجنسين وبصورة متساوية . يحتوي الدم على العديد من الانزيمات بكميات قليلة جدا في

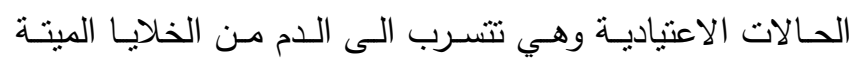

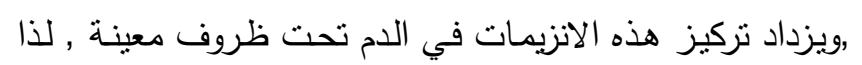

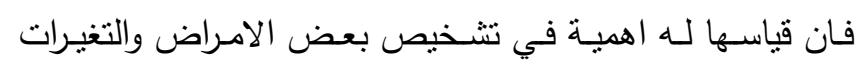
الفسيولوجية في الجسم (20 ). اظهرت قيمـة انـزيم GOT زيـادة معنويـة في الـكور والانـاث

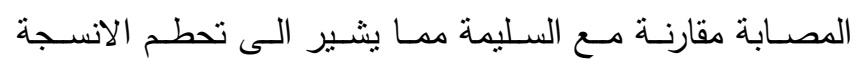

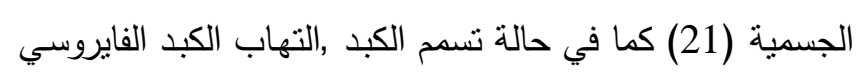

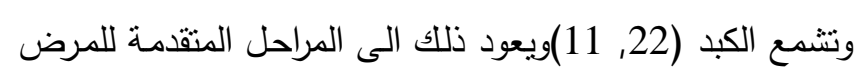

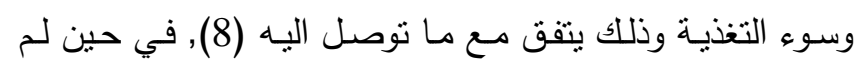

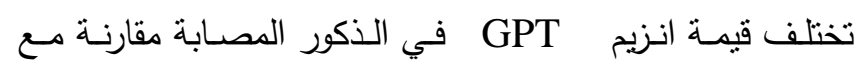
الذكورالسليمة اختلافا معنويا وربما يعود السبب الى ان الاصـابة

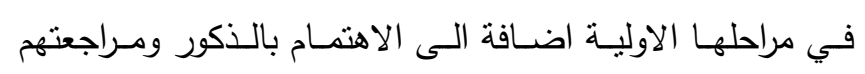

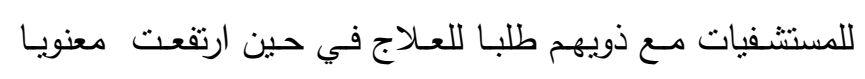
في الاناث المصابة مقارنة مع الاناث السليمة مما يؤكد

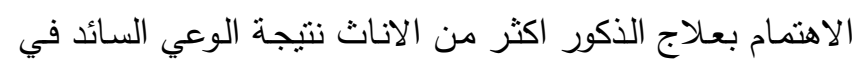

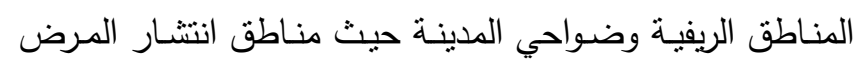

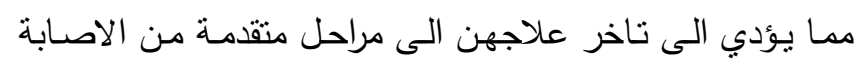

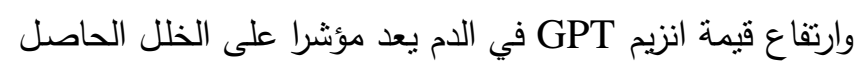

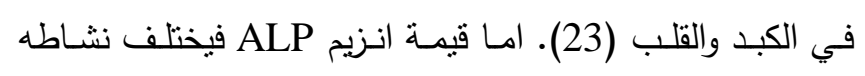

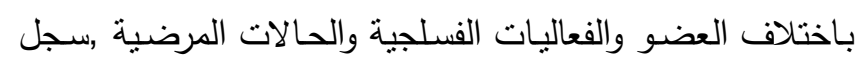

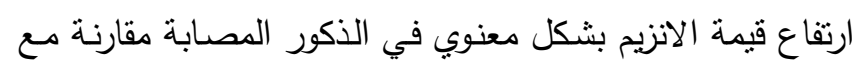

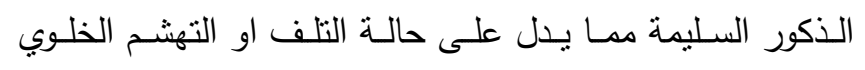

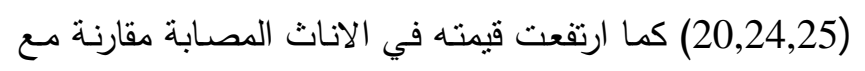
الاناث السليمة ولكن بشكل غير معنوي • تساهم البروتينات في بناء وتركيب الخلية الجسمية , ويقوم

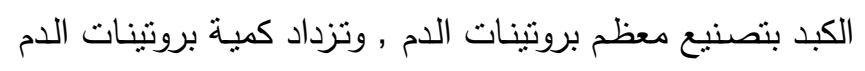
في بعض الحالات المرضية كالتهاب الكبد الفايروسي والتهاب الكبد الحموي وتقل في امراض الكبد التي تعرقل عملية تصنيع

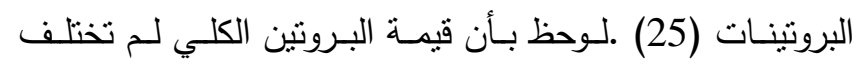


animal reservoirs in Bushehi Province, Islamic Republic Health of Iran.East Mediterr J.7:912-7.

6- Sukkar, F. (1981). Isolation of leishmania from the spleen of adog hn Iraq.Trans.Roy.Soc.Trop. Med.Hyg. 75(6): pp.859-860.

7-Jawetz, M.and Adelbergs, A.(2007).Medical microbiology .24th.ed.McGraw-Hill.Companies .USA.pp.663-665.

8-Rahim.K.M. And Ashkan, M.M. (2007). Epidemiological, clinical and therapeutic features of pebiatric Kala-azar J.Trop. Med. Pub.Health,Vol:38,No:4.

9-Veress.B..(1977). Morphology of the spleen and lymph nodes in fatal visceral leishmaniasis.Immunol.,33 , pp.605-610 .

10-Sundar ,S. ( 2002). Annals of Tropical medicinc and parasitology .vol.96.No.1.p.19-23.

12-Kind, P.R.N. and King, E.J. (1954). Journal of clinical pathology 7:322, cited by Wooton, I.D.P.and Freeman,H.(1982). Microanalysis in medical biochemistry, 6 th. Ed., Churchill Livingstone.

13-Henry.J.,Cannon ,D.C.and Winkehman ,J.W. (1974).Clinical chemistry ,principles and technicques.2nd ed ,Harper and Low .

14-Varely, H. (1980). Practical clinical biochemistry .4 th ed., William Heinmam, Medical Book. London: pp.802.

16- AL-Alak, S.F.(1996).Study in the epidemiologyof visceral leishmaniasis (kala-azar) hn AL-Mager district-missan province.m.sc.Thesis,collage of veterinary medicine,university of Baghdad.

17- Nouri, L.and AL-Jeboori,T.(1973).Kala-azar in Iraq : An epidemiological and clinical study .J.Fac.Med. Baghdad. 15, pp.72-85.

18- Sukkar, F.(1974). Study on sand flies as vectors of Kala-azar in Iraq.Bull.End.Dis.Baghd.15 (2), Pp.85-104.

19- AL-Alousi, T.I. (1980). Detection of antibodies to leishmaniasis in dried blood on filter paper by the indirect fluorescent antibody test. Ann.Trap.Med.Paras.,74(5), pp.503-506.

21-Luxton ,B. and Pallister,C.J. (1999).Clinical biochemistry.Reed Educational and professional publishing Ltd.pp.253.

22-Kaneko,J.J.;Harvey,J.W.and Brucs, M..L. (1997). clinical biochemistry of domestic animals. 5th ed. Academic press .London.pp.932.

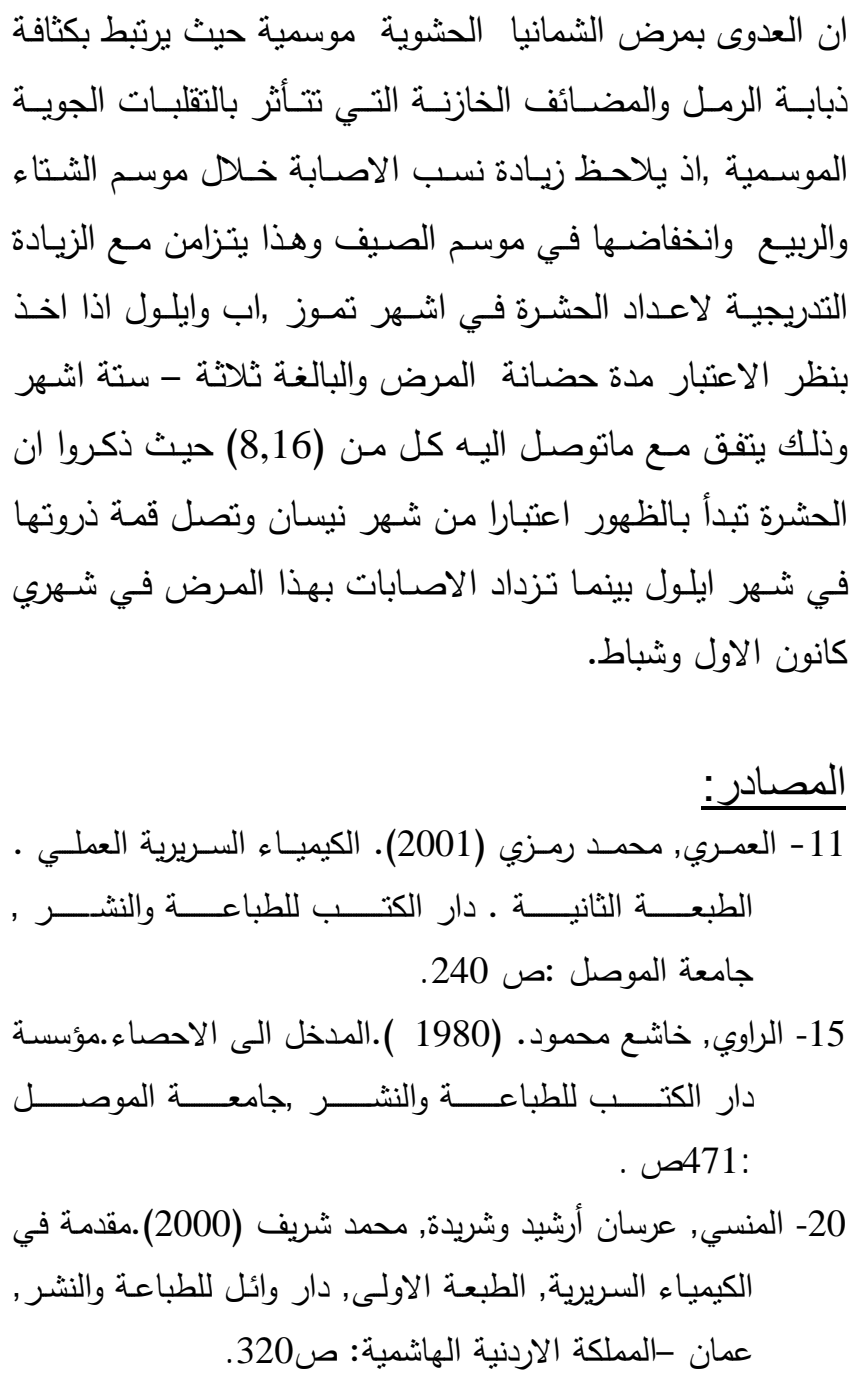

1-Burton, J.B; Clint,E.\&Thomas,N. O.(2005). Human parasitology .3thed.Elsevier Academic Press, USA,PP.101-113.

2-Jeromino, S.; Soursa, A. \&Paeison, R. (2005). Leishmania species visceral (Kalaazar).cutaneous and mucocutaneous leishmania principles and practices of infections disease, 6 th ed., philadephia.saunders.pp.3145-56.

3-Sukkar,F.(1972).Visceral leishmaniasis in Iraq.Bull.End.Dis. Baghd. 13(4), pp.77-83.

4- Rassam, S.W.and AL- Jeboori, T.I. (1973).Kalaazar occurance in and adult .J. Fac.Med. Baghd. 15(2), pp.87-90.

5-Mohebali, $\quad$ M.; Hamzavi,Y.;Edrissian,G.\&. Forozani, A. (2001).Seroepidemological study of visceral leishmaniasis among human and 
26-AL-Juraygan,N.;AL-Ayed,M.;AL-Mugeiren, M.;Boohene A.\&AL-Herbish A.(1992).Visceral leishmaniasis in infancy and childhood ,epidemiology and clinicopathological study of 63 cases in AL- Baha Province Saudi Arabia J. Trop.Pediatr .38.pp.12-6.

27- Latif,B..(1979). The indirect fluorescent antibody test for diagnosis of Kala-azar infection hn Iraq.Ann.Trop.Med. Paras. 73(1), pp.31-35.
23-Coles,E.H.(1986).Veterinary clinical pathology .chapter 16.4th Ed.,W.B.sanuders company ,Philadelphia, USA.486 pp.

24-Rogers,C.,John,H.,Binjamin.G. and David,E. (1995). Principles and practice of A nesthesiology ,V:2, mosby,year book .London. $2067 \mathrm{pp}$.

25-William,J.;Marshell and Stephan,K. B.(2008). Clinical chemistry. 7th.ed. Mosby Elsevier . UK.pp.253-266.

\title{
Physiological and epidemiological studies on Kala- azar disease in Missan Governorate
}

\author{
Zainab A.J.R.AL-Ali \\ Biology department - Science College \\ Missan University
}

Nidhal Abdulla Hashim

Nursing department - Technical Institute-Medical - Amara

\section{Hayder Izaati Aabadi}

\author{
Laboratory department - AL-Sadder general hospital hn Amara
}

\section{Summary:}

The present study was made to known the effect of Kala-azar disease on some biochemical parameters in children. The GOT, GPT ALP, total protein and total bilirubin were measured in 50 infected children for both sex (21 male and 29 female). The research also included the study of (number of infected children and their ages during the 16 last year and months of year).

The results showed significant increase $(\mathrm{P}<0.005)$ in male and high significant $(\mathrm{P}<0.005)$ in female in GOT in the infected children compared with health children .The value of GPT didn't show significant differ in male ,but its show high significant increase $(\mathrm{P}<0.001)$ in the infected female.

The value of ALP show significant increase $(\mathrm{P}<0.005)$ in infected male, while its value didn't show significant different in female. The values of total protein and bilirubin don't reach to significant level in infected children compared with control. The percent of infection differ during the last 16 years ago. High percent in the infected male were record in 2007 (64\%) and low percent in 1995 (41\%), high percent of the infected female were record in 1995 (59\%) and low percent in 2007 (36\%.)

The age of children between 1-2 year recorded high number of infection about (961) case, while the age greater than 5 year recorded low number of infection (31) case. The month of year also effect on the number of infection, high percent of the infection were recorded during Jenuary $(17.7 \%)$ and low percent in Augest (2.4\%). 